\title{
New social reality in the context of information and communication technologies
}

\author{
Aleksandr G. Tyurikov - Nikolay N. Kosarenko - Tatiana B. Gvozdeva - \\ Marianna V. Voronina - Elena Ye. Grishnova - Natalya A. Solovyeva
}

DOI: 10.18355/XL.2018.11.03.06

\begin{abstract}
The paper discussed challenges of the rapidly developing, advancing and updating Information and Communication Technology (ICT) from the point of view of social philosophy. Information and communication technology implies unique knowledge, methodologies, models, and problems that are not easily addressed by the existing Russian sociologists and philosophers, and hence there is a need to study one of the challenges as a subject. Advances in Information and Communication Technology and its accompanying impacts on the society development have led researchers to consider the social and philosophical interpretation of the problem concerning the development of new social reality in the context of information and communication technologies. The study has been based on the methodological principles of social philosophy, transdisciplinary research strategy, the concept of neuromarketing, the concept of neurosociology, and the concept of social reality simulation. The authors considered the problem as a current critical turning point of the history on the basis of interdisciplinary, global approach used to understand the processes penetrating into almost all spheres of life and life support systems and into the development of new institutions related to human development innovations. The survey resulted in the developing a theoretical model to study the role of dynamically developing information and communication technologies in new social reality. Materials of the article confirm the main knowledge increment obtained while studying the challenges is concerned with the role of information and communication technologies in creating and constructing new social reality.
\end{abstract}

Key words: new social reality, information, and communication technologies (ICTs), youth, globalization, Internet

\section{Introduction}

The problem of social and philosophical understanding and interpretation of the importance of dynamically developing ICTs in creating and developing new social reality at the beginning of the XXI century has become urgent for a number of reasons:

1. The modern world is characterized by the increasing role of ICTs due to the fact that they have a strong impact on other top technologies (nanotechnology, biotechnology, cognitive technologies), thereby strengthening the process of globalization, permeating the economy, politics and culture (Orekhovskaya, 2016; Olkhovaya et al., 2016; Katuntsov, Kultan, Makhovikov, 2017; Kvon et al., 2017).

2. The use of these information and communication technologies in business is the key to success in opening up new, unimaginable opportunities. The Internet becomes the place where all the most important things happen, i.e., ideas and companies are born and die, money is earned and spent, etc. (Tyurikov, Shlyapin, 2008). A key success factor here is the ability to create and manage information in the Internet environment in all its guises. These tasks have been stimulating and directing the development of information technologies. In turn, dynamically developing ICTs have the opposite, reverse, effect on the social reality through using them in the creation of

XLinguae, Volume 11, Issue 3, June 2018, ISSN 1337-8384, eISSN 2453-711X 
new social phenomena (together they form new social reality, involving themselves into it and redeveloping the components of the old social reality).

3. Due to the new social realities, there is a significant complication in the social development which is recorded as the social and humanitarian knowledge, primarily as new turns in Sociology, Social Philosophy, Political Science, Economics, etc. (Orekhovskaya, 2014; Gorbunova, Mokeyeva, 2017). One of these turns, fixing the emergence of new social realities, represents a considerable complication of society at the global and local levels that looks like 'global disruption' and 'global chaos.' At the same time, the new realities represent not just chaos, but 'global complexity' which appears to be organized in its own way through moving to the hallmark, information and communication regulators, as well as to the formation of global networks which were established beyond certain societies (Kravchenko, 2012). This requires new theoretical and methodological approaches to be developed in order to understand these turns in social and humanitarian knowledge.

4. The development of ICTs has made it possible to generate so-called 'simulacra' (representations or imitations of persons or things) substituting the reality. We face simulation processes that permeate almost all areas of social life where these simulation processes are qualified as a 'routine,' performance, 'centaurism' (Toshchenko, 2012). The identity and authenticity of a person, social groups, and the civil society are connected with these simulation processes.

It is very important that continuous ICT evolution impacts various aspects of social reality all the time, transforms the way of individuals' and social groups' lives, converges the activities of social and public institutions, management systems of transnational corporations and various enterprises (Knabe et al., 2005). The relevance is that there is an empirical fact according to which the domestic philosophers and sociologists have been lagging in their attempts to comprehend and investigate the rapidly improving and rapidly upgrading ICT, and thus there is a lot to be done in this field.

\section{Research Methodology}

The survey is based on methodological principles of social philosophy, transdisciplinary research strategies, the concept of neuromarketing, the concept of neurosociology, the concept of creating, constructing, social reality, the information approach, the paradigm of the human network perspectives, the theory of complex information societies, and the paradigm of globalization. In the course of social and philosophical research, the categorical apparatus of dialectical philosophy and successful studies related to new social phenomena have been used. The methodological foundation of the research allowed us to show adequate dynamics of ICT development which plays a vital role in the creation, construction, and development of new social reality.

The first methodological ground for the survey is that the heuristic potential of transdisciplinarity study allows us to detect the invariants of the object under study in a variety of sciences (Orekhovskaya, 2016). This transdisciplinary research methodology is very clearly correlated with the social-and-philosophical understanding of the role of ICT in the construction of new social reality and thus makes it the center of research methodologies being used. The importance of transdisciplinarity research strategy lies in the fact that it reveals invariants in the information interaction of different levels of the hierarchically organized social world. This means that it is unfair to reduce the human essence to 'human as an information matrix' that limits ICT application in the construction of new social reality.

The second methodological ground for the study of the ICT importance in the construction of new social reality is neurosociology which practically represents a concretized transdisciplinary research strategy. The significance of the neuropsychological approach lies in the fact that it is able to explain the specific 
mechanisms (starting with neural and ending with social ones) in constructing new social phenomena by means of ICT.

The third one is concerned with the theory of network society. It is the construction of social reality with such tools as a set of information and communication, computer and virtual technologies that led to the emergence of a new type of a society, i.e., a network society with its multimedia.

This means that human activity is immersed in the network society ephemeral symbolic environment that acts as a sort of cocoon for it and due to its dynamism is unstable and unsustainable (Orekhovskaya, 2014). This instability is organically connected with the continuous development of ICT, the evolution of the Internet, improvement of neuroelectronic interfaces, and self-developing computers. Therefore, in the future, we will face new social reality with features absolutely incredible from the non-scientific point of view.

The fourth methodological basis is the noosphere concept of constructing new social reality. Currently, the problem of resource depletion is really acute and underlies the existence of mankind. It has dramatically increased due to exponential growth in the speed and volumes of the resource consumption; this factor brings about the need to build new social reality. The way out here is to implement the proposed by V.I. Vernadsky (1977) concepts of the noosphere that implies new social reality being formed due to and through the use of new technologies, especially information technologies in close connection with nano-, bio - and cognitive technologies.

The fifth methodological basis of the study is the humanistic theory of complex society. Currently, humanity has entered a very complex social environment characterized by non-linear processes, accompanied by various risks and hazards, injuries, gaps and other fundamentally new social vulnerabilities. In this case, the network nature of human capital entails the use of dynamically developing ICT necessary to construct new social reality and the corresponding model of the human individual (Tyurikov et al., 2017).

All these methodological grounds related to ICT are relevant, play a significant role, as they provide an opportunity to explain their importance for the development of the evolving humanity that has been set by the paradigm of the global information space, and the strategy of transdisciplinary research.

\section{Hypothesis}

The hypothesis of the study is that the strategic importance of ICT in the construction of new social reality stems from the fundamental empirical fact that information is one of the main factors, along with the elementary needs of a person in his/her survival, that under the conditions of 'information society' manifests itself through cybernetic-physical (virtual-real) system used for the purpose of both a human and society adaptation to unpredictable threats and hazards arising due to a number of technological revolutions.

\section{Results}

Socio-philosophical understanding of ICT strategic importance for constructing new social reality is possible with the help of an appropriate theoretical model. After all, according to the latest forecasts, the development of mankind is taking place during the digital phase of the information revolution, and we are on the way to the Global Information Society (GIS). In other words, humanity is going to the Global Information Society through the use of ICT and the Internet in its development, and the understanding of this process involves building an adequate multi-component theoretical model.

XLinguae, Volume 11, Issue 3, June 2018, ISSN 1337-8384, eISSN 2453-711X 
The first component of this theoretical model is the concept of e-culture or "multimedia" culture. According to M. Castells (2000), multimedia supports sociocultural patterns characterized by;

a) widespread social and cultural differentiation;

b) increasing social stratification among users;

c) integration of all messages in a common cognitive pattern; and

d) distinction between audiovisual and printed media, popular and learned culture, entertainment and information, education and persuasion (Castells, 2000).

$\mathrm{He}$ considers it as one of the fundamental factors providing a continuous change of social reality that is able to ensure a number of advantages to people and social groups (and society as a whole) on their way to GIS (Castells, 2000). Firstly, there is a constant development of information and computing support for the dynamic nature for socio-economic processes; and the decision-making information and analytical support is significantly expanding (Orekhovskaya, 2016). Secondly, thanks to ICT and the Internet, there has been a shift from the mass standardization and unification inherent in industrial civilization to the individualization of many social phenomena (Yemelin, Thostov, 2013). Thirdly, there is an increase in the information demands of the members of the society which requires e-government strategies (Danilova, 2015).

The second component of the theoretical model of new social reality impacted by ICT development is the concept of the relationship between the natural and the artificial (Bayeva, 2013). However, if the artificial becomes the natural over time in case of a new artificial one having been constructed, then it is almost impossible to detect the border between the natural and the artificial, and this should be borne in mind when considering the problem of the new social reality formation with the help of ICTs developed.

The third component of the theoretical model is a paradigm of the network society. In terms of our study, this means that modern scientific knowledge in the context of an electronic culture built on the Internet and other info communication networks functioning is associated with the paradigms of the network person, the future network society and the concept of physics-and-cybernetic structures (Polikarpova, 2012).

The fourth component of the theoretical model is a hypothesis about the structure of the psyche substrate formulated within the framework of the concept of the historical evolution of information technologies and put forward by S.N. Grinchenko and Y.L. Shchapova (2013). This concept focuses on the meta-revolutionizing system of mankind with the formula 'man + ICT (being used and increasingly complicating)' (Grinchenko, Shchapova, 2013).

The fifth component of the theoretical model is the concept of a programmable society. While creating and constructing new social reality using ITCs (NBICcivilization) the concept of the programmed society is of significance (Kazantsev et al., 2012).

The sixth component of the theoretical model is a probabilistically oriented semantic model of a personality proposed by V.V. Nalimov (2011). It provides a new, original interpretation of the interrelated semantic and physical worlds, the meaning of life and the Universe, multidimensional personality, etc.

All the components enlisted help to explain the increasing differentiation of the ICTs and their transformation potential.

\section{Discussions}

Considering the degree of scientific development of the topic, we have to state that, in the domestic and foreign social and humanitarian scholarly literature, there are social philosophers', sociologists' and economists' reports on the studies of various aspects of the problem that are concerned with the relationship between the new social reality and the ICTs. The issue regarding the impact of modern ICTs on human 
consciousness and the process of social reality creation is considered on the basis of transdisciplinarity approach to the concept of positive construction of social reality (Polikarpova, 2012). It is closely associated with the further development of the Internet, development of converging technologies (NBIC technologies, i.e., nano, bio, info и cogno) and the prospects in modifying (upgrading) the human consciousness and body (we mean e-Homo).

The works pay special attention to such new dynamic and topological factors affecting the functioning ability of the society as the Internet, cybernation of all spheres of human and social activities which manifest themselves through the impact of ICTs on the society and its development (Orekhovskaya et al., 2017). In this case, the importance of ICTs for new social reality assumes their unity with other high converging technologies (nano, bio, info и cogno) without which it is impossible to create and construct new society and ensure the human adequacy (Rambidi, Berezkin, 2008). The new society design through ICTs suggests that the development of the appropriate type of a human capable of using these technologies.

The survey conducted by T.G. Danilova (2015) is of certain interest here as her paper 'Construction of Social Reality' is devoted to a communicative and pragmatic approach to social reality in the discourse of the informative society. The value of pragmatic nature of communicative approach for constructing a social reality on the basis of information society discourse is shown by means of social and philosophical analysis. In other words, a well-defined conceptualization of the problem regarding new social phenomena generated in the process of using communicative technologies has been carried out.

The name of P.A. Stepanenko (2006), a Russian social philosopher, is worth mentioning because he also subjected the role of virtual reality to a thorough investigation. The author pays special attention to the variety of virtual realities (i.e., we should determine and distinguish many virtual realities) and the role of virtual reality in the life of a modern human and society. In this case, the constructing role of virtual reality in the life of the individual and society as a component of ICTs, especially Internet technologies, becomes absolutely clear.

The following important aspects that have been considered in the works of L.V. Bayeva (2013), Ch. Arthur (2013), D. Born (2013) should be considered as well. They emphasized the following features of the Internet:

- the phenomenon paradigm and the Internet have been considered as a sociocultural factor of communication processes;

- the role of Internet communications in reference to the position of Russia in the world has been outlined.

In these studies, 'Internet communications' act as a sociocultural factor that contributes to the construction of new social reality in Russia.

There have been a number of dissertations and monographs written on social philosophy themes that focus on ITCs, Internet technologies and related electronic (multimedia) culture (Orekhovskaya, 2016).

In one of the recent articles titled 'The Babylonian Network: the Erosion of Truth and the Diffusion of Identity on the Internet,' V.A. Emelina and A.Sh. Tkhostova (2013) have discussed the basic functions of the Internet using such metaphors as a library and the Agora. As the result of their study they have drawn the following conclusions: - converging into an unlimited library causes a dramatic increase of information debris and reduction the possibility to evaluate critically the information received;

- relativism as the basis of the Internet makes the issue of identification more complex and appears to be unstable to be used in a coherent and reasonable rooting of a human in reality;

XLinguae, Volume 11, Issue 3, June 2018, ISSN 1337-8384, eISSN 2453-711X 
- like the expanded Agora, the Internet has a side effect, i.e., it reduces the quality of communication and causes loss of the feeling of responsibility for the statements made. Here, the empirical fact is 'captured' according to which the Internet space is to a large extent filled with information garbage and this cannot but affect the construction of social reality.

It is important to recall that ICTs carry a 'cultural package.' Electronic virtual reality has drastically changed the space-time continuum, which results in the emergence of a completely new type of culture: virtual reality culture, i.e., the social reality in a virtual setting, such as chat/discussion/list groups, based on a theoretical framework of social and cultural reality. Hence, electronic (virtual) culture as an activity technology and has its own significant place. In the works of L.V. Bayeva (2013) its four main features have been justified:

- the human has created along with the " second nature "( the world of artificial things) the " third nature -- the world of virtual phenomena integrating the sphere of consciousness and high information technologies;

- the human exists simultaneously in two dimensions - virtual and physical;

- there are interpersonal communication, education, creativity, art and entertainment in the sphere of electronic culture;

- virtual culture is not only an intermediary between the human and the world but also the reality itself that converts the essence and consciousness of the human. In other words, e-culture which constantly created by developing information and communication technologies lies at the heart of new social reality.

Special attention has been paid to the role of information technology in human history by S.N. Grinchenko and Y.L. Shapoval (2013) in their article 'Information Technologies in History.' They consider the place and role of information technologies in the widest sense of the word from the point of view of the following models:

1. Humanity is a self-governing hierarchical system the evolution of which contains moments of information upheavals and technological revolutions at the system level;

2. interpretation of the Humanity's main stages of the historical development is carried out using Fibonacci numbers.

All these model approaches have been compared both with each other and with empirical research materials which indicates the leading role of information technologies in the human development.

In this regard, of considerable interest is the fundamental monograph by A.K. Kazantsev et al. (2012) 'NBIC-Technologies: Innovations Civilization of the XXI Century' in which the status and possible predictors of such breakthrough high technologies as nanotechnology, biotechnology, ICT and cognitive technologies have been discussed. The authors analyzed the current turning point in the human history on the basis of interdisciplinary, global approach to understanding the processes of penetration into almost all spheres of life and life support systems and the creation of new institutions of the innovative human development. This means that these four high technologies form a new, innovative NBIC-civilization of the XXI century.

\section{Conclusion}

The socio-cultural consequences of the ICTs that are continuously developing and being used in the creation and construction of new social reality include:

- the emergence of a modified e-Homo (Polikarpova, 2012);

- augmented virtual reality where robots with artificial intelligence will play the pivotal role (Born, 2013);

- new information threats and hazards (nanobots, the growth of virtual crime, slide weapon killing consciousness, etc.) (Artaur, 2013); 
- the widespread use of mobile education, mobile enterprises, mobile vessels (Tyurikov et al., 2017);

- the emergence of new science, Data Science, without which it will be simply impossible for humanity to exist (Kazantsev et al., 2012).

Knowledge is now recognized as the driver of productivity and economic growth, leading to a new focus on the role of information, technology, and learning. Two major assumptions underlie the role of ICT: the first is that the proliferation of these technologies is causing rapid transformations in all areas of life; the second is that ICT function is to unify and standardize culture. The term 'media culture,' incorporating the phenomena of informational and globalization, is used now and much has been written on the subject of media culture.

There is a reason to be cautiously hopeful and optimistic about the potential of ICTs, especially in view of the relative advantage young people have in embracing these technologies for their own benefit.

The survey proposed may be of theoretical and applied value for the development of relevant areas in social philosophy, sociology and other social and humanitarian disciplines; its theoretic results may be used in the higher education field dealing with organizing and implementing special purpose programs (or targeted programs).

\section{Bibliographic references}

ARTHUR, Ch. 2013. Digital Wars: Apple, Google, Microsoft and the Battle for the Internet. Moscow: AST. ISBN: 978-5-4160-0029-5

BAYEVA, L.V. 2013. E-culture: the Experience of Philosophical Analysis. In: Questions of Philosophy, vol. 5, pp. 75-83. ISSN: 0042-8744

BORN, D. 2013. My Boss is a Robot. In: In the World of Science, vol. 7, pp. 42-45. ISSN 0208-0621

CASTELLS, M. 2000. Information Age: Economy, Society and Culture. Moscow: Academia. ISBN: 5-7598-0069-8

DANILOVA, T.G. 2015. Construction of Social Reality. Moscow: LAP LAMBERT Academic Publishing. ISBN-13: 978-3-659-81850-9; ISBN-10: 365981850X

GOGORA, A. 2017. The text mining of ethics and information technology. In: Communications-Scientific Letters of the University of Zilina, vol. 19, n. 1, pp. 3-8. ISSN 1335-4205.

GORBUNOVA, N.V. - MOKEYEVA, E.V. 2017. Innovative Educational Environment of Higher Educational Institution. In: Man In India, vol. 97, n. 15, pp. 21-40. ISSN: 00251569.

GRINCHENKO, S.N. - SHCHAPOVA, J.L. 2013. Information Technologies in the History of Mankind. In: Information technology, vol. 8, pp. 3-32. ISSN: 2071-8632.

JUROVA, J. 2017. Do the virtual communities match the real ones? (communitarian perspective). In: Communications-Scientific Letters of the University of Zilina, vol. 19, n. 1, pp. 14-18. ISSN 1335-4205.

KATUNTSOV, E.V. - KULTAN, J. - MAKHOVIKOV A.B. 2017. Application of Electronic Learning Tools for Training of Specialists in the Field of Information Technologies for Enterprises of Mineral Resources Sector. In: Zapiski Gornogo intituta, vol. 226, pp. 503-508. ISSN 2411-3336, e-ISSN 2541-9404.

KAZANTSEV, A.K. - KISELEV, V.N. - RUBVALTER, D.A. - RUDENSKY, A.V. 2012. NBIC-Technologies: innovations Civilization of the XXI century. Moscow: INFRA. ISBN: 978-5-16-005468-1

KNABE, G.S. - SHEPEL, V.M. - KLYAGIN, S.V. - TYURIKOV, A.G. 2005. Will Fashion Help us? How do Models and Fashion Styles Work? Fashion as a Means of Promoting the Image, Goods and Services. In: Communication. Culture. Fashion, vol. 1, pp. 34-44. ISBN: 5-7281-0657-9

XLinguae, Volume 11, Issue 3, June 2018, ISSN 1337-8384, eISSN 2453-711X 
KRAVCHENKO, S.A. 2012. Complex Society: the Relevance of the Turns in Sociology, vol. 5, pp. 19-28. ISSN: 0132-1625.

KVON, G.M. - LUSHCHIK, I.V. - KARPENKO, M.A. - ZAITSEVA, N.A. KULKOV, A.A. - GALUSHKIN, A.A. - YAKUPOVA, N.M. 2017. Regional investment policy: analysis and assessment of the investment environment state. In: Eurasian Journal of Analytical Chemistry, vol. 12, n. 5b, pp. 835-853. ISSN 13063057.

NALIMOV, V.V. 2011. Spontaneity of Consciousness. Probabilistic Theory of Meanings and Semantic Architectonics of Personality. Moscow: Academic Project, Paradigm. ISBN: 978-5-8291-1248-6, 978-5-9028-3321-5

OLKHOVAYA, T.A. - SHUKHMANA, A.E. - NEVOLINA, V.V. - AMIROVA, L.A. - ZAITSEVA, N.A. 2016. A synergy-based approach through developing crossdisciplinary module. In: IEJME - Mathematics education, vol. 11, n. 3, pp. 467-474. ISSN 1306-3030

OREKHOVSKAYA, N.A. - TYURIKOV, A.G. - RAZOV, P.V. - KIBAKIN, M.V. - KISELEVA, N.I. 2017. Student Youth Tolerance as a Factor of Socio-Cultural Integration. In: Eurasian Journal of Analytical Chemistry, vol. 12, n. 7, pp. 12831289. ISSN: 1306-3057

OREKHOVSKAYA, N.A. 2014. Social Communication. Moscow: INFRA-M. ISBN: 978-5-98281-387-9

OREKHOVSKAYA, N.A. 2016. On the Definition of "Social Communication". In: Social and Humanitarian Knowledge, vol. 2, pp. 104-109. ISSN:0869-8120

POLIKARPOVA, Ye.V. 2012. Human Consciousness and Processing of Social Information. In: Engineering Science, vol. 7, pp. 253-258. ISSN 1999-9429.

RAMBIDI, N.G. - BEREZKIN, A.V. 2008. Physical and Chemical Bases of Nanotechnology. Moscow: Fizmatlit. ISBN: 978-5-9221-0988-8

STEPANENKO, P.A. 2006. Existential Experience of Virtual Reality. In: Omsk Scientific Bulletin, vol. 2, n. 35, pp.47-49. ISSN: 1813-8225

TOSHCHENKO, Zh.T. 2012. New Faces of Operation: Imitation. In: Socis, vol. 12, pp. 23-36. ISSN: 0132-1625

TYURIKOV, A.G. - SHLYAPIN, D.Ye. 2008. Internet Advertising. Moscow: Dashkov \& Co. ISBN: 978-5-91131-453-8

VERNADSKY, V.I. 1977. Reflections of a Naturalist. Moscow: Science.

YEMELIN, V.A. - THOSTOV, A.S. 2013. Babylonian Network: Erosion of Truth and Diffusion of Identity in the Internet. In: Questions of Philosophy, vol. 1, pp. 7484. ISSN 0042-8744.

Words: 4340

Characters:29 289 (16,27 standard pages)

Prof. Aleksandr G. Tyurikov, Dr.

Department of Sociology, History and Philosophy,

Financial University under the Government of the Russian Federation

49 Leningradsky prospect

1295994, Moscow

Russia

t-ag2013@yandex.ru

Assoc. Prof. Nikolay N. Kosarenko, PhD., PhD.

Department of State Legal and Criminal Law Disciplines

Plekhanov Russian University of Economics

36 Stremyannyi Pereulok Str., 115093 Moscow

Russia

nkosarenko@yandex.ru 
Assoc. Prof. Tatiana B. Gvozdeva, PhD.

Department of Foreign Literature,

Maxim Gorky Institute of Literature and Creative Writing

25 Tverskoy Boulevard, 123104 Moscow

Russia

tbgvozdeva@rambler.ru

Assoc. Prof. Marianna V. Voronina, PhD.

Department of Descriptive Geometry and Graphics

Saint-Petersburg Mining University

$221^{\text {st }}$ Line Str., 199106, Saint Petersburg

Russia

maria.vv@mail.ru

Prof. Elena Ye. Grishnova, Doctor of Political Science

Department of Information Analytics and Political Technologies

Bauman Moscow State Technical University

5(1) 2-Baumanskaya Str., 105005, Moscow

Russia

grishnovaiip@yandex.ru

Assoc. Prof. Natalya A. Solovyeva, PhD.

Department of Criminal Procedure and Criminalistics

Volgograd State University

100 Prospect Universitetsky, 400062, Volgograd

Russia

natalisoul13@mail.ru 